\title{
Urbanized rural areas: Identification, spatiotemporal patterns, socioeconomic characteristics, and impacts on sustainable development
}

\section{Zhichao He}

Martin-Luther-University Halle-Wittenberg

Marcin Spyra

Martin-Luther-University Halle-Wittenberg

Qinghai Guo ( $\nabla$ qhguo@zstu.edu.cn )

Zhejiang Sci-Tech University

\section{Article}

Keywords: sustainable development studies, urbanized rural areas, environmental impact, biodiversity, land degradation

Posted Date: January 20th, 2021

DOl: https://doi.org/10.21203/rs.3.rs-151404/v1

License: (c) (i) This work is licensed under a Creative Commons Attribution 4.0 International License. Read Full License 


\section{Abstract}

Sustainable development studies tend to give urban areas a priority seat, with rural areas cast in an inferior role. Despite of the growing urbanization, rural areas still are homes of billions of people universally suffering from poverty, hunger, disease, poor education. The urbanized rural areas, where population, economy, and built-up land area are higher than urban areas, present the opportunities and challenges to sustainable development. Using large-scale and high-granular spatial data (e.g., population, economy, land-use) from Fujian Province of China, we identified 69, 123, and 213 urbanized rural areas in 1995,2005 , and 2015 from 14,136 village-level administrative units. Spatial agglomeration, proximity to well-developed urban centers, and transportation accessibility are the important spatial factors influencing the development of the urbanized rural areas. Furthermore, we investigated the socioeconomic characteristics of the urbanized rural areas based on the Point of Interest data and found the urbanized rural areas had urban-like housing model, diverse non-agricultural livelihoods, complex road networks, mature public transportation, and better access to medical service. Our results suggest that the urbanized rural areas contribute to sustainable development in terms of economy and society, such as alleviating rural poverty, reducing urban-rural inequality, improving health. However, the environment impacts of the urbanized rural areas should be emphasized because urban-like socioeconomic activities and land conversions toward built-up land may lead to increased energy consumption, land degradation and biodiversity loss in rural areas.

\section{Main Text}

Impacts of rural areas on sustainable development are not inferior to that of urban areas ${ }^{1-4}$. The Sustainable Development Goals (SDGs) arguably relocate rural areas from the margin of our attention to the foreground. Rural areas, where most of people are struggling with poverty (SDGs 1$)^{5-7}$, hunger (SDGs $2)^{8}$, shortage of health care (SDGs 3$)^{9}$, and poor education (SDGs 4$)^{10}$; where agricultural sectors are shrinking the contribution to economy and providing fewer job opportunities (SDGs 8) ${ }^{2}$; where ecosystems are particularly vulnerable to climate change (SDGs 1315$)^{4,11}$, will determine the complete victory of the SDGs.

Against challenges that include urban-biased policies, globalization, technology improvement, rural areas have diverse implications for sustainable development ${ }^{12,13}$. Rural marginalization or rural decline is a global phenomenon ${ }^{14,15}$. In that context, rural areas, characterized by poverty, food shortages, population loss, bear a passive and residual role $2,3,16,17$. The marginal rural areas directly affect the SDGs of no poverty ${ }^{18}$. Indirectly, rural poverty, which accompanies massive rural out-migration, increases the urbanrural gap in living standards that is the main source of inequality within the country ${ }^{19}$. In contrast to the marginal rural areas, the urbanized rural areas perform a progressive, even competitive role when interacting with urban areas. The urbanized rural areas have dramatically transformed their economic, social, cultural, and environmental spaces into more complex ones than ever ${ }^{20-22}$. Such complexity produces different effects on sustainable development. For example, diversifying livelihoods in the 
urbanized rural areas notably promote local economy and alleviate rural poverty ${ }^{23}$. However, the other SDGs, such as land degradation, biodiversity loss, and climate change, might be hardly achievable as local communities alter their approach to farming ${ }^{11}$. In conclusion, sustainable development targeting rural areas is an ambitious project and deserves more attention.

This study focused on the urbanized rural areas that are neither urban areas nor rural areas, but demonstrate features of both ${ }^{24,25}$. We described the peculiarities of the urbanized rural areas from three perspectives: population, economy, and land-use. Firstly, the population mobility in the urbanized rural areas has changed from a unidirectional out-migration to a bidirectional urban-rural migration. As a result, the urbanized rural areas are the rural areas of high population. Secondly, although the people in the urbanized rural areas are farmers, but engage in the various non-agricultural activities (e.g., rural tourism, township and village enterprises, e-commerce company) to increase their incomes. Thus, the urbanized rural areas have a high economic output. Thirdly, while the urbanized rural areas remain a native rural landscape, a considerable amount of land has been transformed into built-up land to accommodate the non-agricultural activities, such as housing, transportation, and industry.

The purpose of this study is to identify the urbanized rural areas and to analyze their spatiotemporal patterns and socioeconomic characteristics. We chose 14,136 village-level administrative units in Fujian Province, China, as study sample (Fig.1). They are legalized grassroots governance units which elects the villagers' committee as its authority ${ }^{26}$, and they are the basic socioeconomic units in rural China (e.g., census, mail system, land ownership) ${ }^{27}$. We selected Fujian Province as the study area, because its rural areas are experiencing diverse transformations. On one hand, the rural marginalization is a common phenomenon in the mountainous and hilly areas due to high elevation, remoteness, and poor endowments ${ }^{28}$. One the other hand, some rural areas have been in situ urbanized, driven by the development of local enterprises ${ }^{29,30}$.

Our study consisted of three steps: identification of the urbanized rural areas, analysis of spatiotemporal patterns and socioeconomic characteristics (Fig. 2 and Method). Firstly, we identified the urbanized rural areas via three indicators: population, gross domestic output (GDP), and built-up land area between 1995 and 2015. Secondly, we analyzed the spatiotemporal patterns of the urbanized rural areas, such as ratio of average nearest neighbor, urban proximity, and transportation accessibility. Finally, we investigated the socioeconomic characteristics based on the Point of Interest (POI) data.

\section{Results}

Agglomeration, urban proximity, transportation accessibility. We identified 69 urbanized rural areas in 1995, 123 in 2005, and 213 in 2015. The ratios of average nearest neighbor were 0.48 (z-score=-8.21, pvalue<0.01), 0.5 (z-score=-10.51, p-value<0.01), and 0.54 (z-score=-12.98, $p$-value<0.01) in 1995 2005, and 2015 , demonstrating that the urbanized rural areas were spatially clustered at the provincial level. Furthermore, the urbanized rural areas were concentrated in eastern coastal regions (Fig.3), which is consistent with the urbanization pattern that there is a higher population density and economic 
development in eastern coastal regions. The spatial agglomeration of the urbanized rural areas is an effective strategy to compete with urban areas and brings important benefits, such as information sharing, cost reduction and efficiency gains, thereby to escape rural marginalization ${ }^{31}$.

Spatiotemporal patterns of the urbanized rural areas. Among the prefecture-level cities, Quanzhou City possessed the greatest number of the urbanized rural areas and experienced the fastest growth in the number of the urbanized rural areas during the study period. Second in rank was Zhangzhou City. Nanping, Sanming, and Ningde City possessed very few urbanized rural areas.

\section{What do the urbanized rural areas look like?}

In 2015, 578,160 POls were distributed in 3,210 urban areas, 12,094 POIs were distributed in 213 urbanized rural areas, and 136,218 POls were distributed in 10,713 ordinary rural areas. Averagely, there were about 180,57 , and 13 POls for each village-level unit in the urban areas, urbanized rural areas, and ordinary rural areas. The urbanized rural areas and urban areas are similar in the top $25 \mathrm{POI}$ categories (Fig.5). This suggests that the urbanized rural areas can be considered as a rudimentary urban area in terms of socioeconomic characteristics.

(1) Urban-like housing model. House number ranked 1 in the urban areas and urbanized rural areas. The urban areas displayed the largest average frequency of house number (19.09). The urbanized rural areas possessed 9.59 and the ordinary rural areas only had 0.76 , suggesting that the urbanized rural areas maintain a higher population than the ordinary rural areas. This finding validates our identification strategy to some extent. Residential quarter ranked 17 in the urbanized rural areas (average frequency $=0.61$ ) and ranked 6 in the urban areas (average frequency $=4.6$ ). In China's rural housing model, villagers typically live in traditional separated family houses with large courtyards. In contrast, residential quarter represents contemporary urban multi-story residential buildings that are rare in rural areas. The presence of residential quarter in the urbanized rural areas results from the state-led urbanization (e.g., displacement and resettlement) ${ }^{36-38}$. In this scenario, villagers would be forced to move from traditional rural houses to modern high-rise apartments which were built by governments. This phenomenon not only changes the morphology of traditional village but also transforms villagers' lifestyles and livelihoods to ones that are more common in urban living environments.

(2) Diversification for non-agricultural livelihoods. Rural and urban areas are significantly different in terms of livelihoods ${ }^{14}$. In the current study, the top $25 \mathrm{POI}$ categories relating to non-agricultural activities were very common in the urbanized rural areas and their average frequencies were significantly higher than those in the ordinary rural areas. For example, the average frequency of company in the urbanized rural areas was 5.41 , which was dramatically higher than 0.54 of the ordinary rural areas. The presence of POI categories relating to non-agricultural activities indicates that villagers in the urbanized rural areas are able to engage in economic alternatives outside agriculture, such as being employees (company), selling clothes (shop of clothing and accessories), catering (Chinese restaurant), so as to increase their incomes locally and dramatically. 
(3) Transportation improvements. In the urbanized rural areas, transportation improvements manifest in two ways: complex road networks (intersection name and street name) and mature public transportation (bus station). The average frequencies of intersection name, street name, and bus station in the urbanized rural areas were $1.48,0.96$, and 1.12 . These POI categories were generally absent in the ordinary rural areas. The urbanized rural areas have been transformed from a one-street layout which is a common spatial layout in rural areas into a network-street layout in order to accommodate the mobility of population and products. In addition, the presence of bus station indicates the urbanized rural areas have been integrated into urban public transport system, which enables villagers more conveniently to commute between their locations and urban areas.

(4) Better access to medical service. In addition to the above changes, significant improvements in medical service are evident in the urbanized rural areas. For example, the urbanized rural areas averagely possessed 0.53 Clinic (ranked 21) and 0.5 pharmacy (ranked 23) in each village-level unit. In the ordinary rural areas, the average frequencies of Clinic and pharmacy were only 0.07 (ranked 22) and 0.04 (ranked 31). The difference suggests that villagers in the urbanized rural areas have better access to medical service and can afford them.

\section{Opportunities, challenges, and policy implications}

Opportunities and challenges. Drawing on the urbanized rural areas, we analyze the impacts of rural development on sustainable development and recommend the corresponding adjustment in policy. The urbanized rural areas positively response to the challenges that rural areas are facing with (e.g., rapid urbanization, globalization) and demonstrate a possible pathway to the revitalization of rural areas. The first significant contribution from the urbanized rural areas is to promote rural economy by diversifying non-agricultural activities, which effectively eradicates rural poverty. Sequentially the effects appear in social dimension. The massive rural-to-urban migration significantly contributes to the rapid urbanization and economic development in China. However, it brings about many negative impacts on society, such as leave-behind children and elders in rural areas, disadvantaged peasant-workers in urban $\operatorname{areas}^{39}$. The urbanized rural areas can bring several social benefits by providing villagers the opportunity to improve incomes without having to leave their homes. For example, villagers can enjoy urban socioeconomic activities and better access to health services without bearing travelling costs to urban areas and increased living costs. Moreover, feeding family at home mitigates social instabilities that includes the loss of social networks, cultural disruption, leave-behind children and elders ${ }^{5}$. More profoundly, the urban-rural gap in terms of living standard will be reduced to form a balanced and inclusive urban-rural relationship ${ }^{40}$. Lastly, but more importantly are environmental outcomes. The high built-up land area in the urbanized rural areas suggests the negative consequences of land conversions toward built-up land, such as loss of farmland, inefficient built-up land use, need to be emphasised. Furthermore, similarities in socioeconomic characteristics between the urbanized rural areas and urban areas indicate that the development of the urbanized rural areas is associated with more urban-like energy consumption that tends to damage vulnerable rural ecosystems. 
Policy implications. As we discussed above, the urbanized rural areas present the opportunities and challenges for sustainable development in terms of economy, society, and environment. We firstly suggest that the urbanized rural areas could play an intermediary role in regional development planning where they develop complementary functions upward with urban areas, meanwhile, strength the linkages downward with the neighboring rural areas. In addition, developing diversified job opportunities is the key to ensure the sustainable rural economies and societies. To do so needs a systematic project that includes skill training, reasonable tax breakers, infrastructure improvements, regulatory environment, and so on. Lastly, steadfast government commitment to environmental protection can assist the urbanized rural areas in capturing socioeconomic opportunities and in minimizing trade-offs from environmental pressures. Local environmental knowledge will be mobilized by this commitment, which can lead to a win-win between socioeconomic development and environment protection in the urbanized rural areas.

\section{Conclusion}

Measuring and mapping rural development can effectively support the policy-making on sustainable development. We spatiotemporally identified the urbanized rural areas via the spatial data of population, economy, and land-use. To our best knowledge, it may be the first attempt to measure and map rural development at such high granularity and at such vast scope. The urbanized rural areas, on one hand, overcome problems caused by urban sprawl (increased living cost, loss of social networks) and by rural marginalization (poverty, hunger, disease, poor education), on the other hand, offer the advantages from urban-like socioeconomic activities (amenity, clean and healthy living environment) and original rurality (natural landscape, cultural cohesion).

The SDGs are proposed as a framework for national action and global cooperation ${ }^{41}$, however, rural villages, the most basic administrative and socioeconomic units in most countries, are the last mile determining the victory of the SDGs and are where the most challenging task falls into. In future, recognition by policymakers and researchers that the opportunities and challenges presented by rural areas could impede the comprehensive achievement of all SDGs, is necessary for relocating rural areas into the center of sustainable development studies.

\section{Methods}

Our method consisted of three steps: identification of the urbanized rural areas, analysis of spatiotemporal patterns and socioeconomic characteristics.

Identification strategy. This study proposes three indicators for identifying the urbanized rural areas: population, GDP, and built-up land area. Justification for choosing these indicators is as follows: (1) the urbanized rural areas have a bidirectional population mobility. Thus, population in the urbanized rural area are higher than rural areas or even urban areas; (2) the urbanized rural areas display economic prosperity (e.g., tourism, e-commerce, and township enterprises) and local people enjoy affluency, as 
reflected by economic output (e.g., GDP); (3) the urbanized rural areas remain the original countryside landscape, but land conversions toward built-up land are prevalent in need of non-agricultural activities.

After selecting the identified indicators, we need to define the urban and rural areas, that is, we need to divide 14,136 village-level administrative units into urban and rural areas. The village-level administrative units are legalized grassroots governance units which has a defined boundary and a unique administrative division code that consists of 12 digits. The division code is published by the National Bureau of Statistics of the People's Republic of China (NBS) and is used for census. Based on the 12 digits' division code, we can search 3 digits' urban-rural continuum code from the NBS (http://www.stats.gov.cn/tjsj/tjbz/tjyqhdmhcxhfdm/2010/index.html). There are 7 types of the urbanrural continuum codes: 111 means that the village-level administrative unit belongs to urban districts of the prefectural city; 112 means the urban-rural conjunction areas; 121 means the central areas of the town; 122 means the town-rural conjunction areas; 123 means the special urban areas; 210 means the central areas of the rural town; 220 means the rural areas. The first digit of the urban-rural continuum code distinguishes urban areas (1) and rural areas (2). Finally, we defined 10,926 village-level units as rural areas and 3,120 village-level units as urban areas (Supplementary Fig.1).

The last challenge is how to identify the urbanized and ordinary rural areas, that is, we need to know how high is the population, GDP, and built-up land area of the urbanized rural areas. We used spatial statistics tools in ArcGIS 10.6 to extract population, GDP, and built-up land area for 14,136 village-level units in 1995,2005 , and 2015 . The 3,120 village-level units in urban areas were used as contrast sample, and their mean values of the three indicators provided the standard of identification. In order for a village-level administrative unit to be classified as the urbanized rural areas, its population, GDP, and built-up land area must all be greater than the corresponding mean values of urban areas. If any one of the three indicators was not satisfied, the village-level administrative unit was classified as the ordinary rural areas.

Analysis of spatiotemporal patterns. For looking for the spatial factors influencing the development of the urbanized rural areas, we investigated the spatiotemporal patterns of the urbanized rural areas identified in 1995, 2005, and 2015. In doing so, we focused on three aspects: (1) the average nearest neighbor ratio; (2) urban proximity; (3) transportation accessibility.

The average nearest neighbor ratio calculated a nearest neighbor index based on the average distance from each urbanized rural area to its nearest neighboring feature. When the ratio is less than 1 , the pattern of the urbanized rural areas exhibits clustering at the provincial level, and when the ratio is greater than 1 , the pattern is dispersed.

Urban proximity represents that the Euclidean distance between the urbanized rural areas and the nearest urban centers. The urban centers refer to the government's seats of 9 prefectural cities and 84 counties in Fujian Province.

Transportation accessibility calculated the Euclidean distance between the urbanized rural areas and main roads. We selected national highways, provincial roads, and county roads. These roads are a 
network of trunk roads, connecting all capitals of provinces, prefectural cities, and most of counties across China.

Analysis of socioeconomic characteristics. The third aim in our research was to investigate the socioeconomic characteristics of the urbanized rural areas. To doing so, we used the POI data which has been commonly used as a reliable data to measure regional socioeconomic activities ${ }^{42-44}$. The POI is a specific point location containing the name, category, latitude, and longitude. The obvious application of the POI data is to mark user's location or destination in Google Maps. Firstly, we summarized the frequency of each third-level POI category within the urbanized rural areas, ordinary rural areas, and urban areas. And then we divided the POIs frequencies by the number of the urbanized rural areas, ordinary rural areas, and urban areas. Finally, we selected the top 25 POls categories according to the average frequency.

Data on the village-level administrative unit. We used the 14,136 village-level administrative units in the study area in 2010 as research units which were divided into two categories: rural areas and urban areas. The data was collected from the local government.

Data on population, economy, and built-up land. By population and economy in our case, we used raster data with spatial resolution of $1 \times 1 \mathrm{~km}$ in $1995,2005,2015$, in which the cell's value represents population or GDP. The data was interpolated based on the economic and demographic census data conducted at the county level, land use data, nighttime light data, and settlement distribution data. To validate the data accuracy, we compared the population and GDP calculated by the raster data with those reported in the statistical yearbook of Fujian Province (Supplementary Table 2). Expect for the population in 1995, the differences between the raster data and statistical yearbook are under $5 \%$. The data accuracy could be acceptable for investigating population distribution and economic development at the village-level unit.

We used land-use land data that was manually interpreted from Landsat Thematic (TM) images from 1995, 2005, and 2015. Image pre-processing, classification, and classification accuracy assessment were completed by Data Center for Resources and Environmental Sciences, Chinese Academy of Sciences. The land-use data contains built-up land, arable land, forest land, grassland, water and bare land. Built-up land contains urban land, rural residential land and other independent built-up land, which is used in our study. We obtained the three data from the Data Center for Resources and Environmental Sciences, Chinese Academy of Sciences (http://www.resdc.cn).

Data on POI. The POI data contains 920,569 records in 2015. Each record has the longitude, latitude, name, and the 3-level categories. There are 20 first-level categories, 185 second-level categories, and 578 third-level categories in the POI data. We used the third-level POls category which enables us to investigate the more detail socioeconomic characteristics. We collected the POI data from Navinfo company (http://www.navinfo.com/en/index.aspx), which is the largest digital map provider in China.

\section{References}


1. Grau, H. R. \& Aide, T. M. Are Rural-Urban Migration and Sustainable Development Compatible in Mountain Systems? Mt. Res. Dev. 27, 119-123 (2007).

2. Liu, Y. \& Li, Y. Revitalize the world's countryside. Nat. News 548, 275 (2017).

3. Ward, N. \& Brown, D. L. Placing the rural in regional development. Reg. Stud. 43, 1237-1244 (2009).

4. Woods, M. Rural geography III: Rural futures and the future of rural geography. Prog. Hum. Geogr. 36, 125-134 (2012).

5. Kline, K. L., Ramirez, L. F., Sum, C., Lopez-Ridaura, S. \& Dale, V. H. Enhance indigenous agricultural systems to reduce migration. Nat. Sustain. 3, 74-76 (2020).

6. Bardhan, P. Globalization and rural poverty. World Dev. 34, 1393-1404 (2006).

7. Liu, Y., Liu, J. \& Zhou, Y. Spatio-temporal patterns of rural poverty in China and targeted poverty alleviation strategies. J. Rural Stud. 52, 66-75 (2017).

8. Sanchez, P. A. \& Swaminathan, M. S. Cutting world hunger in half. Science (80-. ). 307, 357-359 (2005).

9. Weinhold, I. \& Gurtner, S. Understanding shortages of sufficient health care in rural areas. Health Policy (New. York). 118, 201-214 (2014).

10. Friedman, J. et al. Measuring and forecasting progress towards the education-related SDG targets. Nature 580, 636-639 (2020).

11. Silva, J. A., Eriksen, S. \& Ombe, Z. A. Double exposure in Mozambique's Limpopo River Basin. Geogr. J. 176, 6-24 (2010).

12. Ashley, C. \& Maxwell, S. Rethinking rural development. Dev. Policy Rev. 19, 395-425 (2001).

13. Woods, M. New directions in rural studies? J. Rural Stud. 28, 1-4 (2012).

14. Li, Y., Westlund, H. \& Liu, Y. Why some rural areas decline while some others not: An overview of rural evolution in the world. J. Rural Stud. 68, 135-143 (2019).

15. Markey, S., Halseth, G. \& Manson, D. Challenging the inevitability of rural decline: Advancing the policy of place in northern British Columbia. J. Rural Stud. 24, 409-421 (2008).

16. Li, Y., Jia, L., Wu, W., Yan, J. \& Liu, Y. Urbanization for rural sustainability - Rethinking China's urbanization strategy. J. Clean. Prod. 178, 580-586 (2018).

17. Yang, X. J. I. N. China's Rapid Urbanization. Nature 342, 310-311 (2013).

18. Guo, Y., Zhou, Y. \& Liu, Y. Targeted poverty alleviation and its practices in rural China: A case study of Fuping county, Hebei Province. J. Rural Stud. (2019) doi:10.1016/j.jrurstud.2019.01.007.

19. Young, A. Inequality, the Urban-Rural Gap, and Migration. Q. J. Econ. 1727-1785 (2013) doi:10.1093/qje/qjt025.Advance.

20. Gao, J. \& Wu, B. Revitalizing traditional villages through rural tourism: A case study of Yuanjia Village, Shaanxi Province, China. Tour. Manag. 63, 223-233 (2017).

21. Ibrahim, M. B., Zulu, L. C. \& Bein, F. L. Settlement in Transition: a Transformation of a Village into a Small Town in Western Sudan. Urban Forum 29, 85-106 (2018). 
22. Lin, Y. E-urbanism: E-commerce, migration, and the transformation of Taobao villages in urban China. Cities 91, 202-212 (2019).

23. Niehof, A. The significance of diversification for rural livelihood systems. Food Policy 29, 321-338 (2004).

24. Zhao, J., Zheng, X., Dong, R. \& Shao, G. The planning, construction, and management toward sustainable cities in China needs the Environmental Internet of Things. Int. J. Sustain. Dev. World Ecol. 20, 195-198 (2013).

25. Xiao, L., He, Z., Wang, Y. \& Guo, Q. Understanding urban-rural linkages from an ecological perspective. Int. J. Sustain. Dev. World Ecol. 24, 37-43 (2017).

26. Wang, R. \& Tan, R. Patterns of rural collective action in contemporary China: An archetype analysis of rural construction land consolidation. J. Rural Stud. 79, 286-301 (2020).

27. Li, Y., Fan, P. \& Liu, Y. What makes better village development in traditional agricultural areas of China? Evidence from long-term observation of typical villages. Habitat Int. 83, 111-124 (2019).

28. Wang, C., Gao, B., Weng, Z. \& Tian, Y. Primary causes of total hamlet abandonment for different types of hamlets in remote mountain areas of China: A case study of Shouning County, Fujian Province. Land use policy 95, (2020).

29. Zhu, Y. In Situ Urbanization in Rural China: Case Studies from Fujian Province. Dev. Change 31, 413434 (2000).

30. Wu, C. "Beyond the Boundary": A Countermovement to the Hollowing-out of Rural China. Mod. China 41, 355-371 (2015).

31. Meijers, E. \& van der Wouw, D. Struggles and strategies of rural regions in the age of the 'urban triumph'. J. Rural Stud. 66, 21-29 (2019).

32. Shen, J. \& Lin, L. State-sponsored and spontaneous urbanization in Fujian province of China, 19822010. Cities 60, 420-427 (2017).

33. Sui, D. Z. \& Zeng, H. Modeling the dynamics of landscape structure in Asia's emerging desakota regions: a case study in Shenzhen. Landsc. Urban Plan. 53, 37-52 (2001).

34. Polèse, M. \& Shearmur, R. Why some regions will decline: A Canadian case study with thoughts on local development strategies. Pap. Reg. Sci. 85, 23-46 (2006).

35. Camarero, L. \& Oliva, J. Thinking in rural gap: mobility and social inequalities. Palgrave Commun. $\mathbf{5}$, 1-7 (2019).

36. Jiang, Y., Waley, P. \& Gonzalez, S. 'Nice apartments, no jobs': How former villagers experienced displacement and resettlement in the western suburbs of Shanghai. Urban Stud. 55, 3202-3217 (2018).

37. Li, J., Wang, F., Wuzhati, S. \& Wen, B. Urban or village residents? A case study of the spontaneous space transformation of the forced upstairs farmers' community in Beijing. Habitat Int. 56, 136-146 (2016). 
38. Zhang, M., Wu, W. \& Zhong, W. Agency and social construction of space under top-down planning: Resettled rural residents in China. Urban Stud. 55, 1541-1560 (2018).

39. Meng, X. People Flocking to China's Cities. Science (80-. ). 343, 138-139 (2014).

40. Zhang, R., Jiang, G. \& Zhang, Q. Does urbanization always lead to rural hollowing? Assessing the spatio-temporal variations in this relationship at the county level in China 2000-2015. J. Clean. Prod. 220, 9-22 (2019).

41. Sachs, J. D. et al. Six Transformations to achieve the Sustainable Development Goals. Nat. Sustain. 2, 805-814 (2019).

42. Dong, L., Ratti, C. \& Zheng, S. Predicting neighborhoods' socioeconomic attributes using restaurant data. Proc. Natl. Acad. Sci. U. S. A. 116, 15447-15452 (2019).

43. Keramat Jahromi, K., Zignani, M., Gaito, S. \& Rossi, G. P. Simulating human mobility patterns in urban areas. Simul. Model. Pract. Theory 62, 137-156 (2016).

44. Krause, C. M. \& Zhang, L. Short-term travel behavior prediction with GPS, land use, and point of interest data. Transp. Res. Part B Methodol. 123, 349-361 (2019).

\section{Figures}

a. Administrative hierarchy

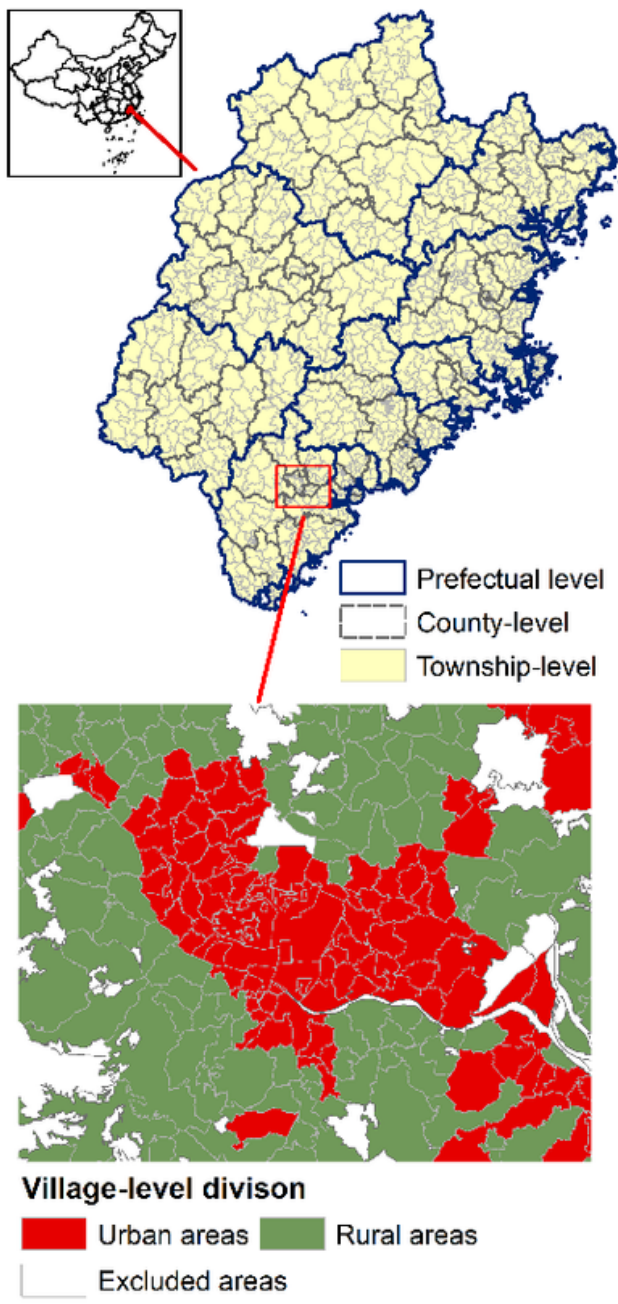

b. Elevation

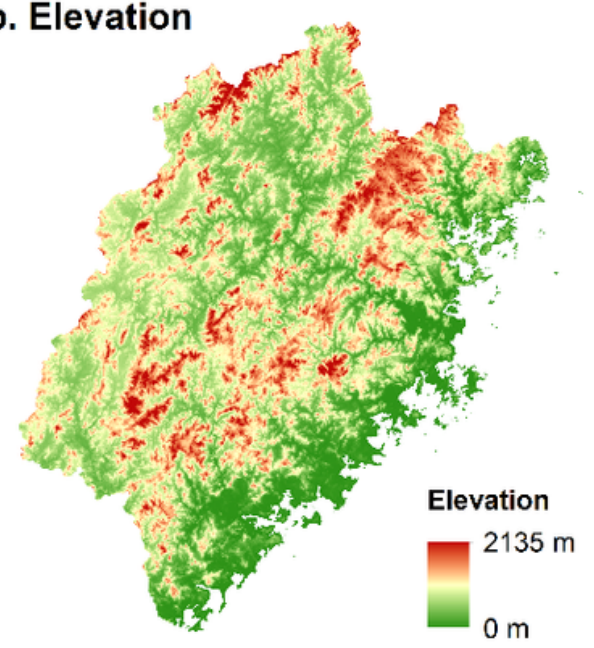

d.

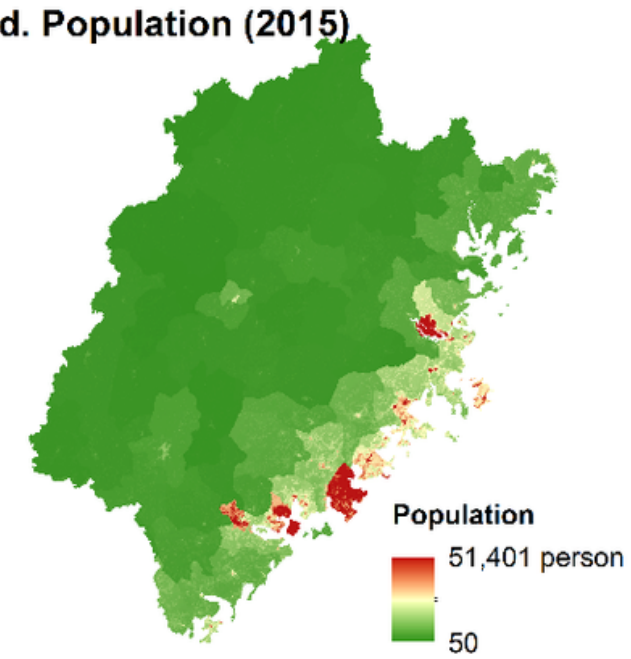

c. Land-use type (2015)

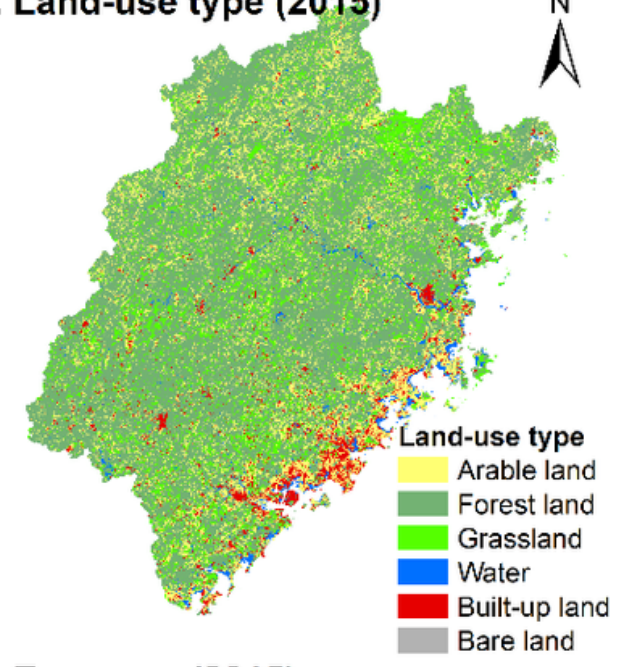

e. Economy (2015)

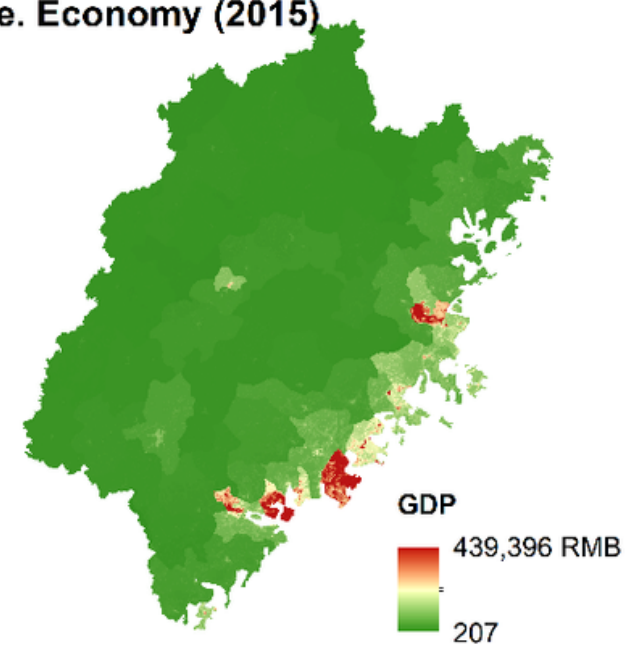




\section{Figure 1}

Study area. (a) Administrative hierarchy: The administrative hierarchy of China is practically divided into five levels: provincial, prefectural, county-, township- and village-level. Fujian Province has 9 prefecturallevel cities, 84 counties, 1,263 towns and 14,136 village-level units. The village-level units are categorized into urban and rural areas based on the administrative division code (Method). (b) Elevation: The topography of Fujian Province is dominated by mountains and hills. (c) Land-use type. (d) Population and (e) economy: Population and economic development are mainly concentrated in the eastern coastal areas. Note: The designations employed and the presentation of the material on this map do not imply the expression of any opinion whatsoever on the part of Research Square concerning the legal status of any country, territory, city or area or of its authorities, or concerning the delimitation of its frontiers or boundaries. This map has been provided by the authors. 


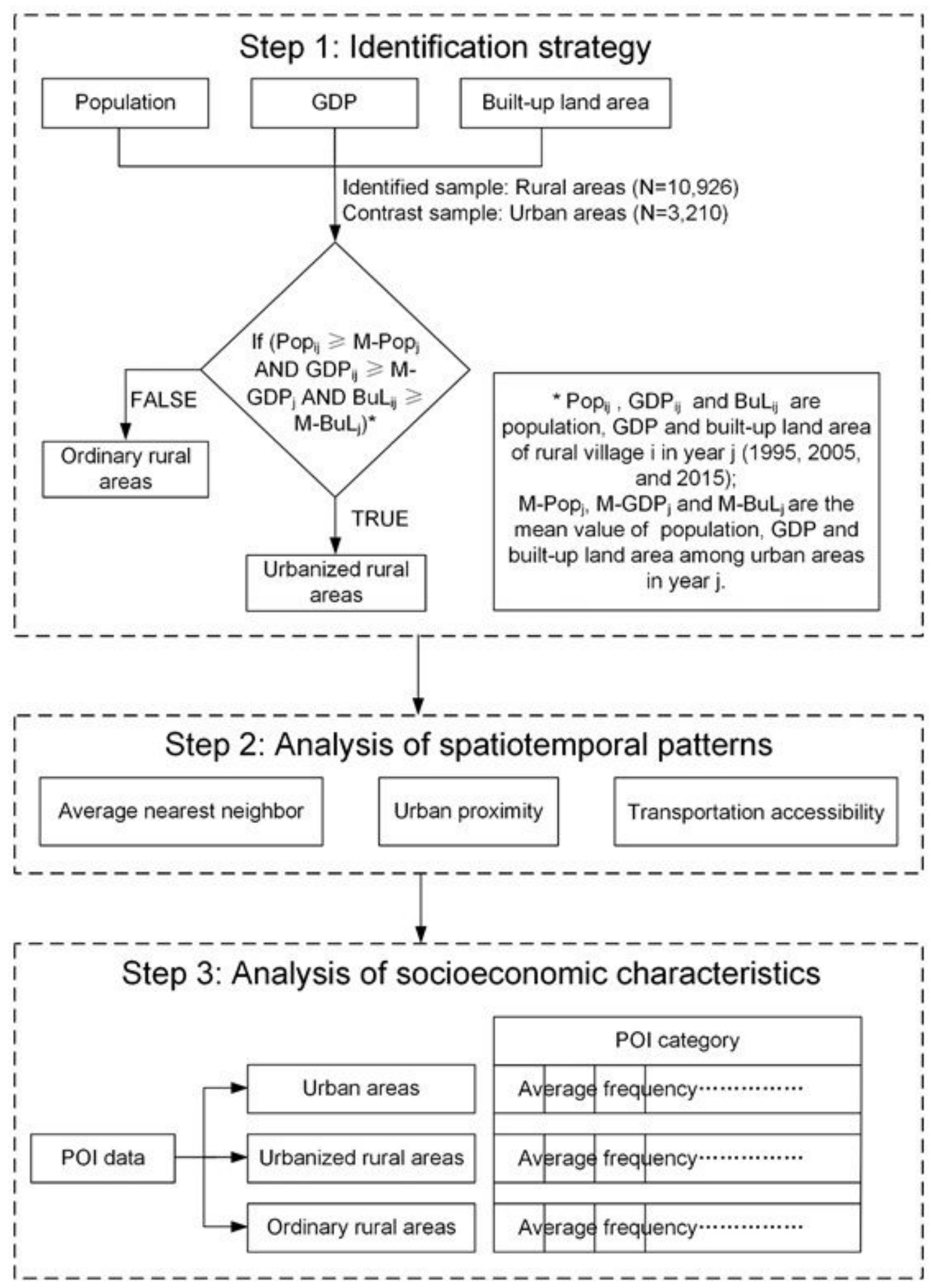

Figure 2

Research process. 


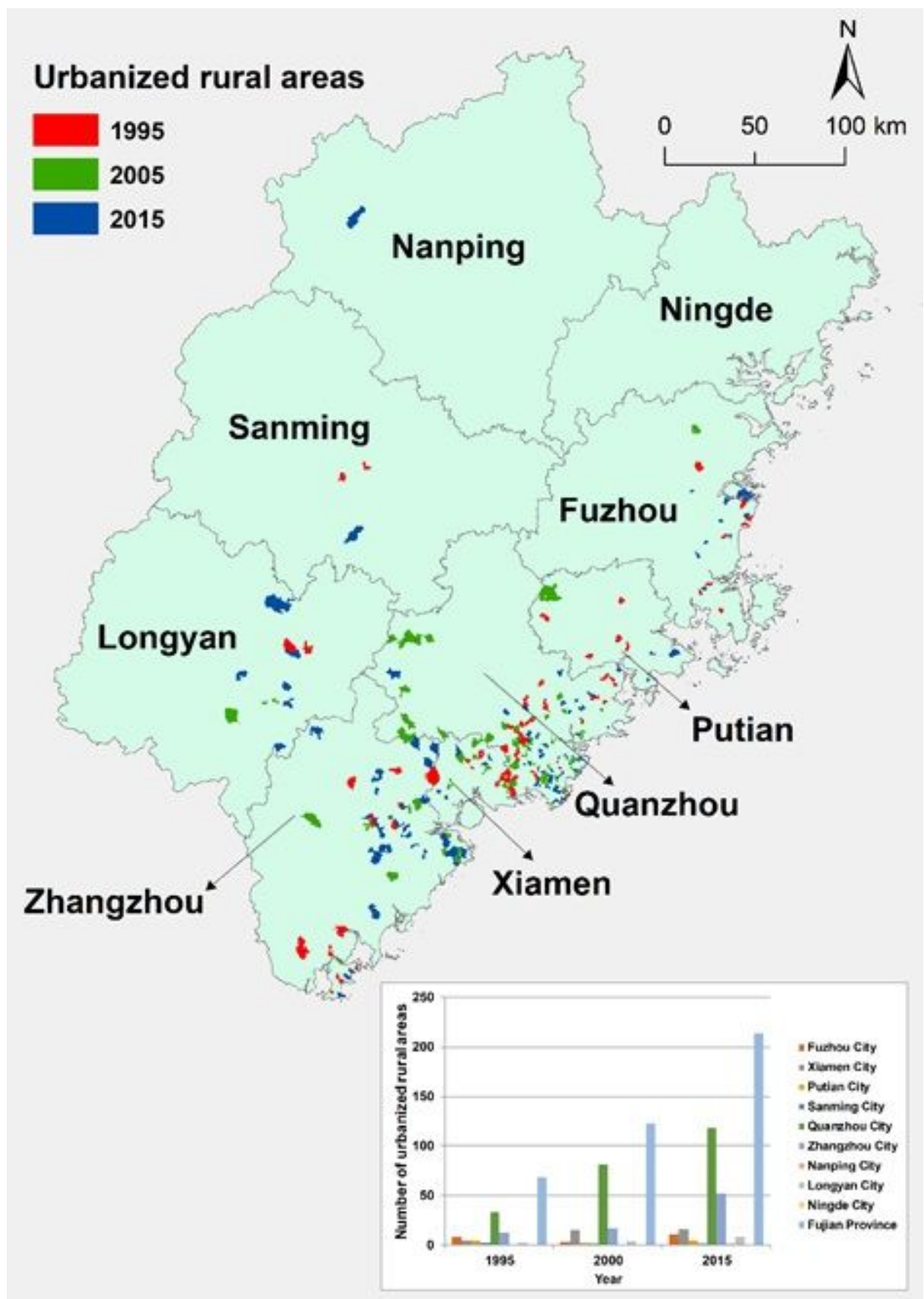

\section{Figure 3}

Spatiotemporal patterns of the urbanized rural areas. Among the prefecture-level cities, Quanzhou City possessed the greatest number of the urbanized rural areas and experienced the fastest growth in the number of the urbanized rural areas during the study period. Second in rank was Zhangzhou City. Nanping, Sanming, and Ningde City possessed very few urbanized rural areas. Note: The designations employed and the presentation of the material on this map do not imply the expression of any opinion whatsoever on the part of Research Square concerning the legal status of any country, territory, city or area or of its authorities, or concerning the delimitation of its frontiers or boundaries. This map has been provided by the authors. 

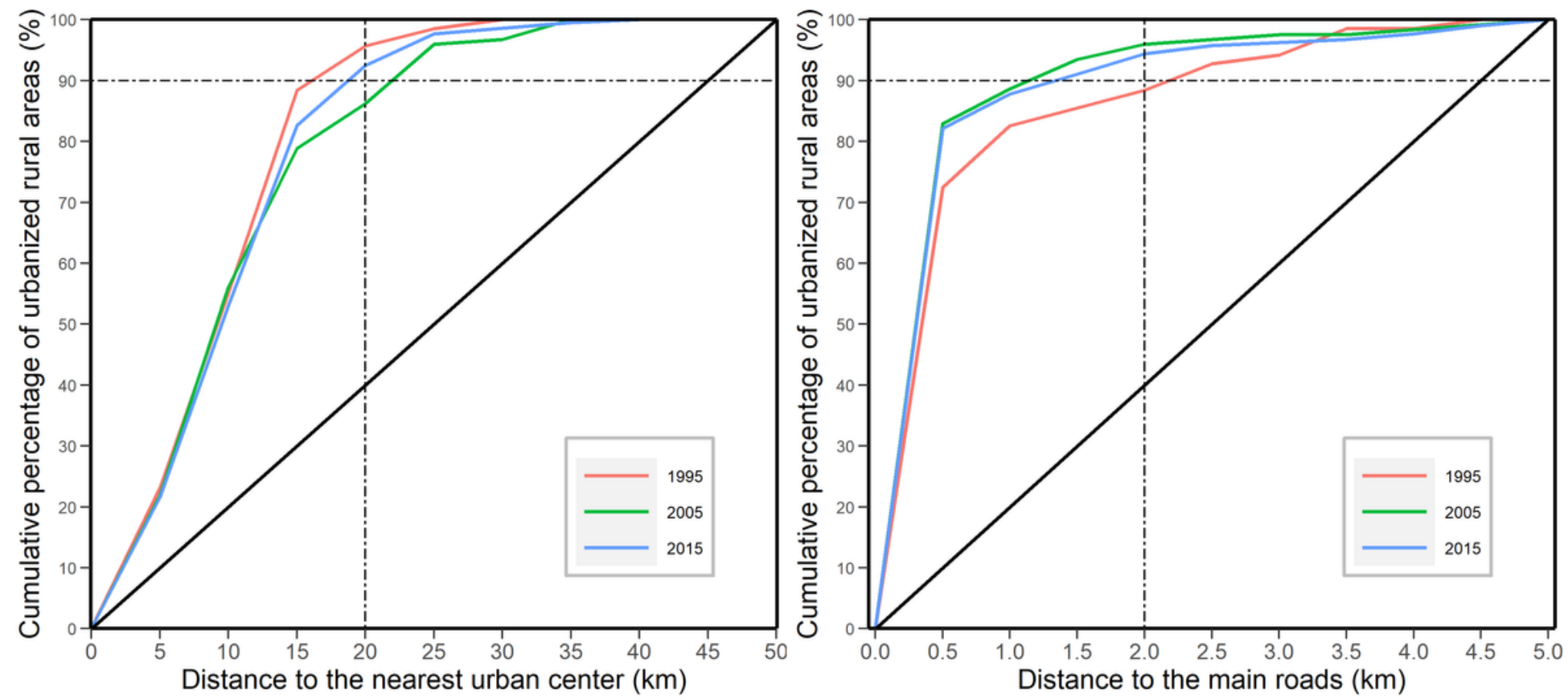

Figure 4

The relationships between urban proximity, transportation accessibility and the urbanized rural areas.

\section{Urban areas}

\begin{tabular}{l} 
1: House number (19.09) \\
2: Company (12.58) \\
3: Shop of clothing and accessories (9.16) \\
4: Chinese restaurant (8.21) \\
5: Other shop (6.95) \\
6: Residential quarter (4.6) \\
7: Shop of home decoration and building materials (4.56) \\
8: Exclusive shop (4.55) \\
9: Shop of living services (4.39) \\
10: Shop of hair and beauty services (4.26) \\
11: Place name at the village level (4.12) \\
12: Convenience shop (3.48) \\
13: Intersection name (3.29) \\
14: Hardware shop (3.24) \\
15: Other restaurant (2.15) \\
16: Fast-food restaurant (1.86) \\
17: Home appliances shop (1.85) \\
18: Lottery shop (1.73) \\
19: Street name (1.68) \\
20: Pharmacy (1.66) \\
21: Bus station (1.59) \\
22: Clinic (1.47) \\
23: Trainning school (1.4) \\
24: Supermarket (1.34) \\
25: Other government agency (1.28) \\
\hline
\end{tabular}

\section{Urbanized rural areas}

\begin{tabular}{l} 
1: House number (9.59) \\
2: Place name at the village level (7.2) \\
3: Company (5.41) \\
4: Intersection name (1.48) \\
5: Shop of home decoration and building materials (1.34) \\
6: Shop of clothing and accessories (1.31) \\
7: Other shop (1.31) \\
8: Chinese restaurant (1.26) \\
9: Mountain (1.21) \\
10: Bus station (1.12) \\
11: Convenience shop (1.05) \\
12: Street name (0.96) \\
13: Supermarket $(0.93)$ \\
14: Public toilet $(0.9)$ \\
15: Exclusive shop (0.78) \\
16: Hardware shop (0.7) \\
17: Residential quarter (0.61) \\
18: Government agency under the township level (0.6) \\
19: Lottery shop (0.59) \\
20: Shop of living services (0.56) \\
21: Clinic (0.53) \\
22: Primary school (0.52) \\
23: Pharmacy (0.5) \\
24: Home appliances shop (0.49) \\
25: Other place name (0.46) \\
\hline
\end{tabular}

\section{Ordinary rural areas}

\begin{tabular}{|c|c|}
\hline \multicolumn{2}{|c|}{ 1: Place name at the village level (6.13) } \\
\hline \multicolumn{2}{|l|}{ 2: Mountain (0.83) } \\
\hline \multicolumn{2}{|l|}{ 3: House number $(0.76)$} \\
\hline \multicolumn{2}{|l|}{ 4: Company (0.54) } \\
\hline \multicolumn{2}{|c|}{ 5: Government agency under the township level $(0.25)$} \\
\hline \multicolumn{2}{|l|}{ 6: Primary school $(0.21)$} \\
\hline \multicolumn{2}{|l|}{ 7: Chinese restaurant $(0.2)$} \\
\hline \multicolumn{2}{|l|}{ 8: Intersection name (0.19) } \\
\hline \multicolumn{2}{|l|}{ 9: Other place name (0.18) } \\
\hline \multicolumn{2}{|l|}{ 10: Bridge name (0.15) } \\
\hline \multicolumn{2}{|l|}{ 11: Street name (0.14) } \\
\hline \multicolumn{2}{|c|}{ 12: Buddhist and Taoist temple (0.13) } \\
\hline \multicolumn{2}{|c|}{ 13: Other government agency $(0.11)$} \\
\hline \multicolumn{2}{|l|}{ 14: Public toilet (0.11) } \\
\hline \multicolumn{2}{|c|}{ 15: Government agency at the township level $(0.1)$} \\
\hline \multicolumn{2}{|l|}{ 16: Township hospital (0.08) } \\
\hline \multicolumn{2}{|c|}{ 17: Shop of home decoration and building materials $(0.08)$} \\
\hline 18: Bus station (0.07) & Socioeconomic characteristics \\
\hline 19: Clinic (0.07) & Housing model \\
\hline 20: Kindergarten $(0.07)$ & Non-agriculturalization \\
\hline 21: River $(0.07)$ & Transportation \\
\hline 22: Petrol station (0.07) & Medical service \\
\hline 23: Convenience shop (0.06) & Other \\
\hline 24: Other shop $(0.06)$ & \\
\hline 25: Factory $(0.06)$ & \\
\hline
\end{tabular}

\section{Figure 5}


Average frequency of the top $25 \mathrm{POI}$ categories in the urbanized rural areas, ordinary rural areas, and urban areas in 2015. The top $25 \mathrm{POI}$ categories were divided into: housing model, non-agriculturalization, transportation, medical service, and other. The numbers in parentheses represent the average frequencies of the POI categories. For example, the average frequency of house number in the urban areas was 19.09, which indicates that each village-level unit in urban areas had $19.09 \mathrm{POI}$ for house number. The explanation of the top $25 \mathrm{POI}$ categories is in supplementary Table 1.

\section{Supplementary Files}

This is a list of supplementary files associated with this preprint. Click to download.

- SupplementaryMaterials.pdf 